\title{
The problem of the overuse of the fossil fuel to produce electricity
}

\author{
Wanlin Guo \\ School of North China Electric Power University ,Bao Ding
}

Keywords: fossil fuel,electricity

\begin{abstract}
As society and the technology develop, most of the power to be used might be electricity. An unavoidable reality is that fossil fuels such as coals are deeply embedded in our energy system. Take China as an example; about half of China's coal gives $80 \%$ of the country's electricity supply (Heinberg, 2010). In recent times, this kind of power has mostly come from the fossil fuels which are formed from prehistoric plants and animals that lived hundreds of millions of years ago. Soon, there might be no more fossil fuels if they are used without limit and human could not find new resources to use instead of fossil fuel.
\end{abstract}

\section{Introduction}

Due to the fact that the fossil fuels are cheap to use and could bring high profits for big companies, they are overused. From the data, the US, China, and Japan consume 31,253,000 barrels of oil daily which means that those three countries produce 1,406,385,000 gallons of oil a day. It takes millions of years for fossil fuels to evolve, therefore if they are used too quickly, there will be no more to be exploited. As the third world's largest energy producer after USA and Russia, China's energy resources are below the average of the whole world because of the overuse of the fossil fuel.( Wu \& Li, 1995, p.167-178 ). Although there are some new resources found to use, the demand of fossil fuels will grow, which is not as fast as it did in the past (ROTTY \& M.WEINBERG, 1977).

\section{Analysis}

Some problems happened because of the overuse of fossil fuels. It has been widely known that not only large amount of energy, but some harmful gases as well are released, when fossil fuels are burned to create the energy. The environment has already been polluted a lot as coal and oil produce plenty of carbon dioxide and sulphur dioxide (Norton, 1999-2015). There might be more carbon dioxide which is known as one of the direct factors to lead to the global warming if more fossil fuels are burnt. Also, sulphur dioxide cooling effects means that the anthropogenic sulphur dioxide may produce a great cooling effect on climate (Lelieveld \& Heintzenberg, 1992). Conventional oil and natural gas extraction are linked to such a lot earthquakes. Fracking, which is one of the most common ways to exploit the oil and natural gas, can lead to earthquakes (Fischetti, 2012).

Although some problems have influenced humans' daily life, the future of the electric energy is optimistic. As the technology develops, several new resources appear available. Officially, renewable energy is defined as energy coming from sources which could be regenerated, such as wind power, water power, and solar power. The research into these new resources has found that they could not only produce a large amount of energy for electricity, but also cause less pollution than those fossil fuels. Governments pay high attention to develop renewable energy sources in order to ease those problems which result from the overuse of fossil fuels (Liu, Li, \& Luo, 2013). A basic technology of hydropower has been proved to be a safe, reliable and cost-effective resource for electricity producing (Jones, 2005). Bernie Bernfeld, chairman of the city's Electric Utility Commission, said 'Wind and gas have a construction cost, but after you build a wind farm, the fuel is free' which means that renewable energy might not only reduce the carbon emissions, but enhance the economy of the world in the future as well. Indeed, wind energy now has already competed with fossil fuels in several places, including Texas, and Denmark, where 30\% of electricity consumption is coming from wind energy (Trancik, 2014). However, the distribution 
might be a setback of renewable energy. It is not uniform for the distribution of renewable energy across the globe which means the imbalance of these energy supplies are probably inevitable (Azarpour \& Suhaimi, 2013). More attention might be paid to research the renewable energy so that humans can adjust best to the local conditions of those resources.

Improving the technology of generators to raise efficiency might be another solution to the problem. It seems to be easier to improve the operating efficiency of existing electric generators than find out a new resource to use instead of fossil fuel. A professor of Bangladesh University of Engineering and Technology said that to save the use of natural gas, efficiency improvement of boilers and co-generation of energy could be a good way (Efficient Usage Can Save 543mmcfd Gas, 2015). Due to the high prices of energy, the production and consumption policy of energy ought to minimize energy loss in the area of agriculture, household appliances, and especially industries (Higher-efficiency generator minimizes energy loss, 2014). For government of rising the efficiency of generators is an essential method to achieve the policy. Building on GE's extensive study about High-temperature Superconducting (HTS) materials and generators, a new kind of generator with a higher efficiency has been invited to save the energy (Murphy, 2003). All in all, the factor which could directly decide the efficiency of generators is whether technology advanced or not. However, it might be extremely difficult for humans to put the higher efficiency generators into daily life because of the lack of the materials and the huge amount of the cost.

Improving the technology of generators to raise efficiency might be another solution to the problem. It seems to be easier to improve the operating efficiency of existing electric generators than find out a new resource to use instead of fossil fuel. A professor of Bangladesh University of Engineering and Technology said that to save the use of natural gas, efficiency improvement of boilers and co-generation of energy could be a good way (Efficient Usage Can Save 543mmcfd Gas, 2015). Due to the high prices of energy, the production and consumption policy of energy ought to minimize energy loss in the area of agriculture, household appliances, and especially industries (Higher-efficiency generator minimizes energy loss, 2014). For government of rising the efficiency of generators is an essential method to achieve the policy. Building on GE's extensive study about High-temperature Superconducting (HTS) materials and generators, a new kind of generator with a higher efficiency has been invited to save the energy (Murphy, 2003). All in all, the factor which could directly decide the efficiency of generators is whether technology advanced or not. However, it might be extremely difficult for humans to put the higher efficiency generators into daily life because of the lack of the materials and the huge amount of the cost.

Energy internet seems to be a good theory to solve the problems that result from the overuse of fossil fuels. The energy internet is also called 'THE FREEDM SYSTEM' which includes a plug-and play interface, an energy router and an open-standard-based operating system (Huang, 2011). Each part of the community could collect the energy and put it into the internet of energy to meet the needs from daily life (Liang Hao; Long Weiding, 2011). Making a link between renewable energy sources and the internet might enhance the world sustain economic development (Yumkella, 2014). The Internet of Things (IoT) and the Smart Grid (SG) are the bases of the energy internet which means that the visions of SGs and IoT have recently been put together into the Internet of Energy (IoE) (Nicola Bui, 2012). In February 2008, during a sudden cold snap, thousands of wind turbines were out of work in the west of TEXAS because the normally relentless winds fell silent which led to part of the state slowed to a halt. If there were a few hundred megawatt hours of energy to supply, that windless interval would have been a non-event. However, it is hard and expensive to store the energy in large quantities. (Lindley, 2010). It is the energy internet that might solve the problem, energy which is stored into the internet might be used at any emergency moment. As what was said above, energy internet is just a kind of theory without any actions to be taken, there is a hope that the coming 'The Third Industrial Revolution' might achieve the energy internet which bring human into a new era of the energy. 


\section{Summary}

It can be seen that the problem of the overuse of the fossil fuels has already influenced humans' daily life a lot. This essay has showed the drawbacks of overusing fossil fuels and three effective solutions related to the problem. As the resources suggest that both renewable energy and the energy internet might be the most significant things in the area of the electricity generating, distributing and storing. Also, the improvement of the generators ought to be paid more attention so that less fossil fuels would be exploited and less natural hazard would happen.

\section{Reference}

[1]. Azarpour, A., \& Suhaimi, S. (2013, 2). A Review on the Drawbacks of Renewable Energy as a Promising. Arabian Journal for Science and Engineering vol.38, pp. 317-328.

[2]. Efficient Usage Can Save 543mmcfd Gas. (2015). Energy Bangla.

[3]. Fischetti, M. (2012). Fracking Can Cause Earthquakes, but So Can Oil and Gas Extraction. scientific american.

[4]. Heinberg, R. (2010, 11 7). The end of cheap coal. nature vol.468, pp. 367-369.

[5]. Higher-efficiency generator minimizes energy loss. (2014, 6 22). IRAN DAILY. 